\title{
SYSTEMS AND MODELS OF INTELLIGENT CONNECTION AND INTERACTION FOR SOCIETY 5.0
}

\author{
SISTEMAS Y MODELOS DE CONEXIÓN E INTERACCIÓN \\ INTELIGENTE PARA LA SOCIEDAD 5.0
}

\author{
Mario Buono \\ University of Campania Luigi Vanvitelli \\ mario.buono@unicampania.it

\section{Giovanna Giugliano} \\ University of Campania Luigi Vanvitelli \\ giovanna.giugliano@unicampania.it
}

Recibido: 4 de enero 2021 / Aceptado: 2 de marzo 2021

Resumen: La necesidad de diseñar nuevos modos de interacción para el disfrute de los entornos urbanos y el Patrimonio Cultural incluye el componente relacionado con el factor experiencial, la memoria y la posibilidad de explorar los diferentes niveles de conocimiento.

El objetivo del diseño es visualizar los contenidos y mejorar el intercambio y la difusión de la información. Partiendo del análisis de los nuevos desafíos de la sociedad hiperconectada y centrada en los datos, y de los actuales modelos y sistemas inteligentes de fruición avanzada e interactiva. El artículo ofrece una visión general de algunas de las innovaciones principales que han caracterizado los cambios en la sociedad contemporánea en términos de usabilidad y accesibilidad. Al analizar los fenómenos contemporáneos, será posible delinear un mapa completo de las características del enfoque y la clasificación de las variables, directrices para el diseño de nuevos sistemas y modelos de conexiones e interacciones para la «Sociedad 5.0» inteligente y creativa. Esta nueva visión podrá absorber las innovaciones de la cuarta revolución industrial y mejorar la productividad en apoyo de los problemas sociales.

A lo largo de los años se han desarrollado soluciones digitales y virtuales que han cambiado la fruición de los entornos urbanos proponiendo modelos de «ciudades inteligentes» que se configuran como lugares digitales y flexibles. El diseñador, reinterpretando las tecnologías de interacción, reorganiza las habilidades del usuario, aumentando el conocimiento social al cambiar las experiencias e interpretación de los contextos urbanos para configurar nuevas formas de «humanización». 
Palabras clave: Sistemas inteligentes, Sociedad humana, Modelos interactivos, Conocimiento aumentado, Tecnologías de interacción, Sociedad 5.0.

Abstract: The need to design new modes of interaction for the enjoyment of urban environments and Cultural Heritage includes the component related to the experiential factor, memory and the possibility of exploring the different levels of knowledge.

The role of design is to visualise content and improve the sharing and dissemination of information. Starting from the analysis of the new challenges of the hyper-connected and datacentric society, and of the current models and intelligent systems of advanced and interactive fruition, the contribution gives an overview of the most significant innovations that have characterized the changes in contemporary society in terms of usability and accessibility. By investigating contemporary phenomena, it will be possible to outline a complete map of the characteristics of the approach and classification of the variables, guidelines for the design of new systems and models of connections and interactions for the intelligent and creative « 5.0 Society». This new vision will be able to absorb innovations from the fourth industrial revolution and improve productivity in support of social problems.

Over the years, digital and virtual solutions have been developed that have changed the fruition of urban environments by proposing models of «intelligent cities» that are configured as digital and flexible places. The designer, reinterpreting the technologies of interaction, reorganizes the user's skills, increasing social knowledge by changing the experiences and interpretation of urban contexts to configure new forms of «humanization».

Keywords: Smart Systems, Human Society, Interactive Models, Augmented Knowledge, Technologies of Interaction, Society 5.0

\section{The material dimension of digital technologies}

In order to make the society of the near future sustainable, we cannot think of stopping the digital revolution. We must work to find a new balance between human and technology, aiming to create places that improve the quality of life. Government policies and companies' strategic choices must be focused on the person's growth and on the development of new skills with high added value. Granelli (2016) summarises in six trends the contribution of technology to the transformation of society due to the natural integration of the physical and digital worlds (through networked sensors, actuators and object-integrated hardware and 
software). In particular, the trends concern the transformation of production processes, which are becoming flexible, hybrid and hyper-personalised; the revolution of mobility, in which travel, work and communication methods will change in favour of new interactive devices. There will be an evolution of learning; in the era of information overload, knowledge obsolescence, and progressive biological forgetfulness, remembering, learning, and creating will take on new meanings. The augmented human challenge will move from the post-human era of «augmented humanity» to the diffusion of soft technologies. An era in which algorithms will dominate the control and management of society and new ethical issues will arise for security, anonymity and privacy. This integration of new technologies and services into current technological systems is transforming the contemporary context into a place where innovation is the driving force of society. Indeed, it increases the complexity of the social fabric to the benefit of the user's lifestyle and well-being.

The new 5.0 Society was created to address challenges that, in addition to the digitisation of the economy or processes, concern the digital transformation of society. To achieve this goal, the Keidanren, Japan Business Federation, published in 2016 a document describing the strategies with which to address contemporary challenges, that will require the demolition of what are called the «Five Walls».

The Wall of the Ministries and Agencies: formulation of national strategies and integration of government promotion system. The Wall of the Legal System: development of laws toward implementation of advanced techniques. The Wall of Technologies: formation of the knowledge foundation. The Wall of Human Resources: dynamic engagement of all citizens in the new economy and society. Lastly, the Wall of Social Acceptance: integration of advanced technologies and society. (Keidanren, 2016)

Analysing the last point, it is possible to observe that Keidanren emphasizes the need to pursue a social consensus by deepening the social and ethical implications, reorganizing and reconfiguring human-machine relations. From these new forms of collaboration, intelligent systems are configured that amplify the skills and performance of users and operators who reach previously impossible levels of productivity. In the past, digital tools were used to automate processes; today increasingly sophisticated technologies allow humanmachine interaction, reinventing social and business processes.

Designing the relationships between technologies, society and users means experimenting with new ways of transferring knowledge starting from dynamic and narrative structures configured according to contemporary techniques and tools. The immaterial 
dimension of digital technologies allows new forms of multidimensional and multisensory expression. In the near future, innovative information-based technologies such as the Internet of Things (IoT), artificial intelligence (AI), 5G network and robotics will bring added value to the social network. The impact of emerging technologies - information technology, telecommunications, bioengineering, robotics and advanced materials technology - would lead to what Maldonado (1994) defines as a progressive thinning of the materiality of the world to a dematerialization of our reality as a whole. The universe of material objects has now begun to contract, replaced by increasingly immaterial processes and services.

\section{Models for advanced and interactive fruition}

Countless changes have defined new ways of experiencing urban spaces and cultural sites. Innovations and rapid technological development have enabled advanced, digital and «augmented» use of environments, providing new forms of knowledge and experience for a wide range of users and encouraging new strategies for promoting and enhancing the area. Over the years, digital solutions have been configured that have changed the way Cultural Heritage is enjoyed and have altered the way how urban environment is experienced, proposing a new model of «smart» city. They are configured as digital, flexible and accessible spaces. Today, technologies such as virtual reality, augmented reality, offer reproductions and representations of works, places and cultural sites in a «realistic» way, by changing the dissemination of information and knowledge. These technologies allow the user a multisensory immersion in previously unexplored and inaccessible contexts.

In fact, current technologies are able to create a perceptual illusion in which the senses are stimulated to the point where cognitive and emotional models consistent with the environment being experienced are developed. Environments such as virtual reality are able to provide the user with sensations similar to those, he would experience in the nonsimulated world such as smells, tactile or haptic sensations. (Morganti, Riva, 2006)

New models of visualization and communication within urban and museum contexts modify the interaction between user, system and perceived space, allowing an immersive experience between the real and the virtual.

The first level of interaction with the surrounding environment is established when the user interfaces with devices or digital systems during his experience. This physical interaction takes place through the use of new communication and visualization systems. Intelligent interfaces that change and adapted to the user to improve the fruition and meet 
the user's different needs and requirements, becoming less and less intrusive.

Sophisticated tools for the use of information are able to transfer constant inputs to the user, which are modified and updated in real time. The devices designed for virtual and augmented reality allow immersion in three-dimensional models with which the user establishes a physical interaction in accordance with the real one, facilitating the acquisition of information.

The second level of interaction is established when the user begins to interact with devices that can adapt and transfer information immediately understandable, give input and allow the user an intuitive use with the context.

The third and last level of interaction is linked to the perceptive components that allow the immersed user to live a new experience, become an actor and actively interact with the works through the support of new technologies. This allows to live an illusory experience, which is perceived through the senses and amplified by immersive technologies that allow a new spatial-temporal cognitive collocation. (Capece \& Giugliano, 2018) The ability to interact with non-real contexts lies in the opportunities provided by new digital tools to recreate and visualise information that appears to the user as new forms of knowledge and understanding.

\section{Towards a Hyper-Connected and Datacentric Society}

The introduction of innovative interaction models integrated with artificial intelligence systems, Big Data and 5G networks, are facilitating the connections, the diffusion and the monitoring of the environments. Such systems can improve the models of urban fruition.

In this scenario, the digitisation of the urban context presents itself as a driving force for the full implementation of accessibility requirements, with interventions to upgrade social models and improve inclusive fruition through formal, technological and perceptual devices.

Among the interventions of reconfiguration of the urban fruition modalities, through the increase of the diffusion of information in the cities, the project LinkNY of the company Intersection is identified. In the last years, the company has spread more than 2000 installations of information and connection stations in the city of New York and all over the world. Intersection has adopted the User Experience in the design process, meeting the needs of citizens and tourists. In fact, the totems scattered throughout the city integrate advanced technological systems that provide information to guide the tourist through the process of discovering the city. The system helps residents to be informed about local businesses and 
provides information on public transport for pedestrians. These are key information to improve the user experience and the accessibility of the city. Through the combination of technologies such as Wi-Fi connection, mobile phone charging stations, fiber optic network and digital sensors, new forms of access to city services and interactive experiences are configured.

The company Telia is testing at Finavia airport, in Helsinki, the possibility of using new systems to provide passengers with new experiential modes. Telia is dealing with how passengers and airport staff respond and interact with the autonomous service robot. This robot is able to improve the connection of spaces and optimize the monitoring of the operations carried out through data analysis. The $5 \mathrm{G}$ robot is also an assistant and guide for passengers in the terminal. In addition, it can provide video streams in real time and allows you to monitor the terminal area remotely or independently and verify the proper functioning of airport operations.

Another suggestive experience is the drone Amazon PrimeAir project, which is experimenting with Amazon in Cambridge. Equipped with artificial intelligence systems and optical sensors that allow it to move in space avoiding any obstacle, this device takes off and lands vertically in a way very similar to a helicopter. It can deliver loads of up to 2.5 kilos, which is the weight of most deliveries that Amazon makes every day and it can cover a distance of about 15 kilometres in half an hour. This device facilitates logistical processes, reducing traffic, while respecting environmental sustainability.

In reflecting on the consequences of technological progress since the early 1990s, designers, essayists and lecturers at the Royal College of Art, such as British designers Dunne \& Raby, lead us to pause and reflect on the future of today's technologies. The most recent perspective vision is currently on display in the exhibition United Micro Kingdoms (UmK): A Design Fiction at the Design Museum in London. The exhibition stages an indefinite future, in which England has been divided into four «microreigns»: those of the Digitarians, the Communist-Nuclearists, the anarchic-evolutionists and the bio-democrats. Each of them has its own political ethics, its own economic system and its own way of life. These kingdoms have been conceived as a hypothesis of the future potential of our society, which allows us to question its desirability. Among the projects on display is Digicar, [Fig.1] autonomous electric vehicles controlled by computers that can carry only one user with a variety of speeds, routes and levels of comfort determined by a tariff system that guides their movement. These devices are able to constantly calculate the best and cheapest route, thus minimising journeys 


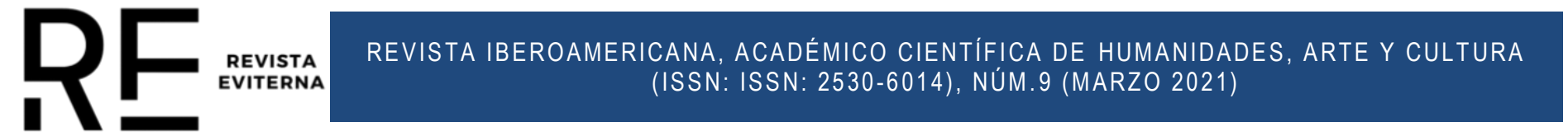

with a view to urban sustainability.

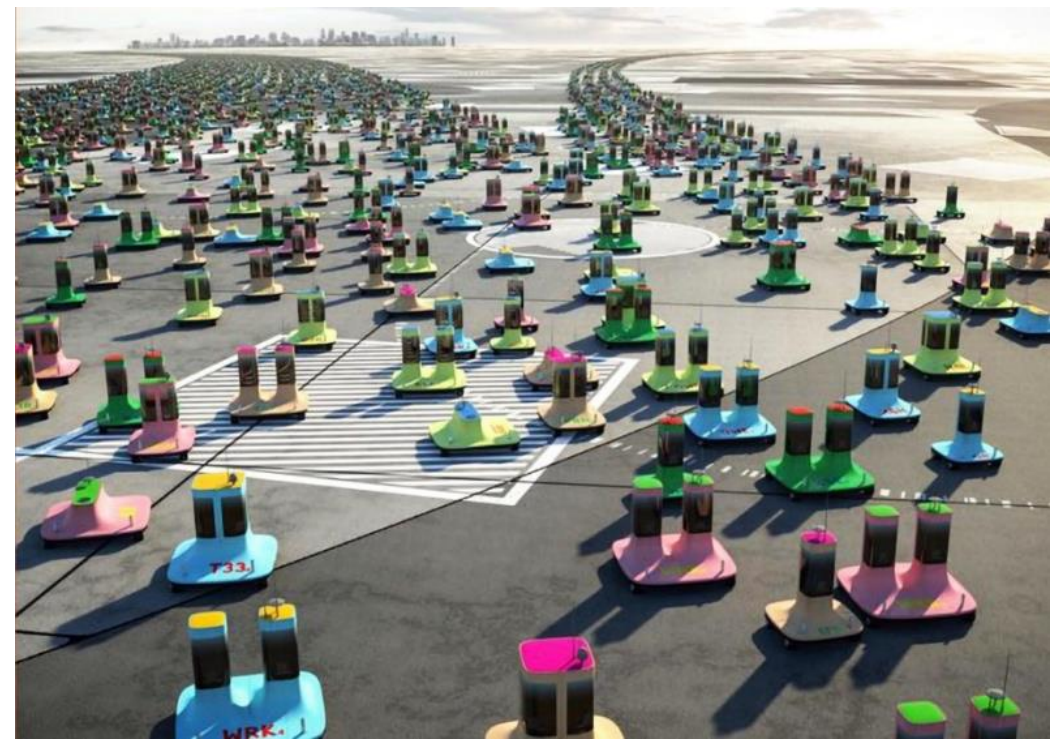

Fig. 1: Digicars by Dunne \& Raby.

\section{Digital solutions for Cultural Heritage}

The possibility of interacting with museum environments or sites that no longer exist thanks to simulation and virtual immersion technologies represents the opportunity to make Cultural Heritage accessible and to enhance it.

In order to guarantee accessibility and interaction capacity, devices will have to ensure a constant synergy between the parties. It is necessary to consider the factors that affect and modify the user's needs - physical, cultural or cognitive - by promoting universal forms of communication.

In 2019, at the Egyptian Museum in Turin, the temporary installation «Invisible Archaeology» was inaugurated. The aim of the installation is to illustrate the principles, tools, examples and results of the work of recomposing the information obtained on finds dating back to the Egyptian era. The exhibition is a virtual tour to discover the history of mummies and unique discoveries, a combination of digital and material culture and a new way of living museum spaces. The invisible becomes visible thanks to technologies such as archaeometry and video-mapping that reveal hidden layers of the finds, releasing distant and unknown stories. Thanks to the skilful use of these technologies, it is possible to reconstruct ancient excavations and discover, for example, what is hidden under the bandages of mummies, without compromising the value of the object. 
In terms of accessibility and usability, augmented reality is one of the technologies that allow exhibitions, events and museums to offer new ways of enjoying and engaging visitors. In 2017, at the Museum of Santa Giulia in Brescia, the Smart Glass Epson Moverio [Fig.2] were used by visitors to walk through the archaeological areas and move freely in the environments. This allows an immersive experience enriched by additional information about places, historical events and their characters. In fact, Smart Glass have been designed with ease of use, durability and accessibility in mind, to offer innovative and more advanced experiences and content than is currently available.

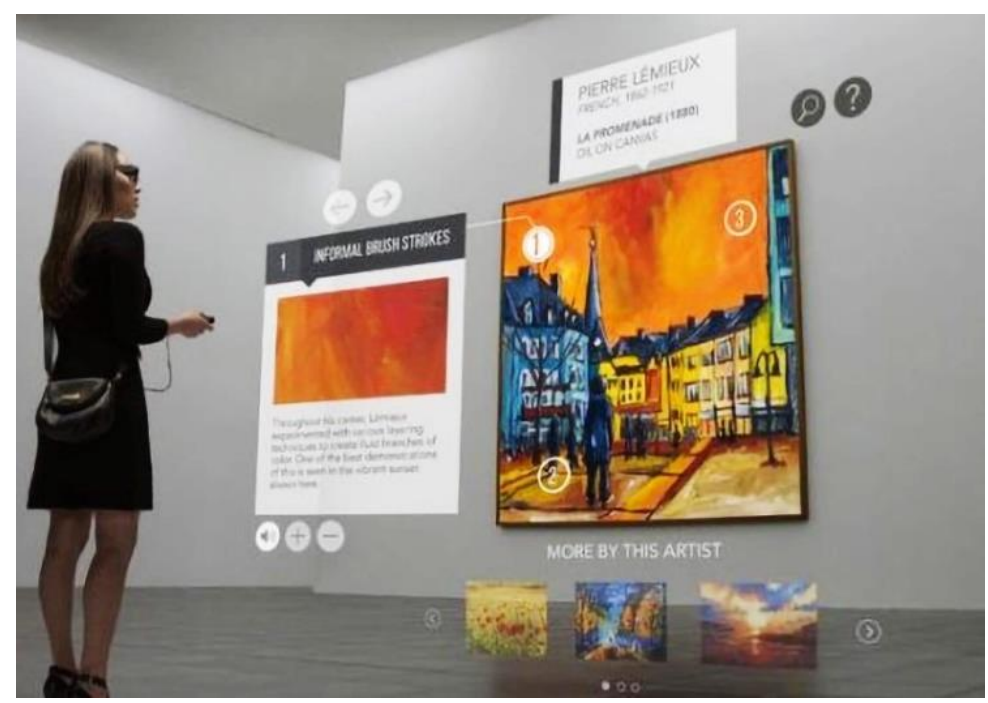

Fig. 2: Smart Glass by Epson Moverio.

Due to its cutting-edge technology and to the use of augmented reality, visitors to museums and exhibitions will no longer have to use their imagination to hypothesize contexts and imagine places. Augmented reality content will be superimposed on the real world to create an engaging experience and make culture more accessible and interesting, while keeping the element, the exhibition or the place visited at the centre of attention.

The Museum für Kommunikation in Berlin showcases objects from the past and the future, through a permanent exhibition that makes the origins, development and future prospects of the information society tangible and experiential. Since 2016, three robots have been welcoming visitors; these robots are configured to inform and entertain the user. [Fig.3] With these, the user establishes an interaction before entering the rooms that house the museum exhibition, helping to orient him, to know and deepen what will be the exhibition path that will host them. This expedient also helps children to approach the experience of fruition in new ways, generating curiosity and attractiveness towards the museum and what they will know. 


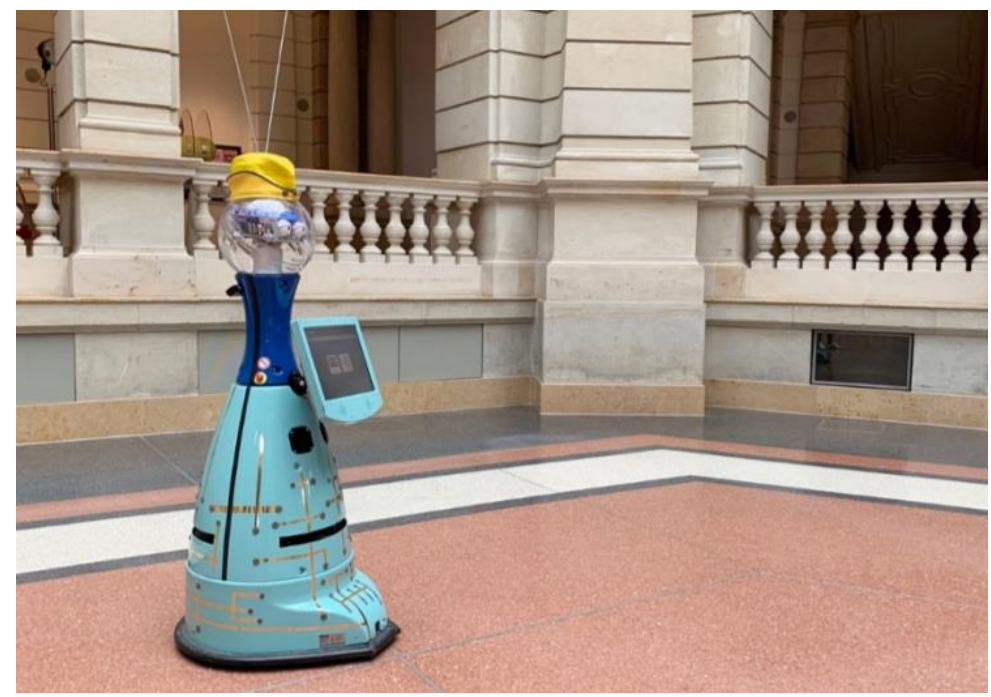

Fig. 3: Robot of Museum für Kommunikation in Berlin

\section{Guideline for designing new connections and interactions}

Contemporary society is characterized by changes that affect the way we interact with the surrounding environment, in everyday life as well as in the fruition of Cultural Heritage. We are witnessing digital transformations that change the methods of communication and offer new forms of information and dissemination of knowledge, through technological devices that improve the quality and experience of use as well as ensuring monitoring, enhancement and protection of the Heritage. Technological innovations, combined with new forms of interaction and dissemination of information that respect and ensure accessibility and usability, become essential factors in order to support new ways of awareness and knowledge of culture. (Giugliano \& Laudante, 2020)

The spread of the distributed network in space modifies the human-machine binomial, generating a new interactive human-network-space relationship. A new equation that according to Ratti (2013) concerns the physicality of space and brings together several disciplines, those dealing with the design of space, such as architecture, planning and design, those focused on technology, such as computer and electronic engineering and the disciplines involved in human-machine interaction. (Giugliano, Capece \& Buono, 2020)

The connections between human and machine become «digital relations» and assume such a symbiotic value that configure expedients which renew the boundaries between the natural and artificial worlds. The paradigm shift sees human-machine interaction undergo a radical renewal; the interconnection and the cognitive processes 
become regeneration factors for interactions that modify human-human relations and dematerialize the barriers between them and the technological systems.

From the configuration of new scenarios and models and from the changes in society, the need arises to design new ways of interaction for the use of cultural heritage and urban contexts.

Ratti \& Claudel (2017) propose using design as a systematic exploration of possible futures. The aim is to apply the method we call «futurecraft» - the art of building the future - by hypothesising future scenarios, examining consequences and needs and sharing the outcomes. Therefore, it involves moving away from current reality by placing the designer within a fictitious but possible future, with the intention of helping to realise or preclude it, through public debate. «Futurecraft» aims to positively influence the future. In methodological terms, it dispels prediction anxiety and opens up new directions for research. Ultimately, the public will steer technological development in the most desirable directions.

This involves the need to include the user through an amplification of skills, considering the experiential factors, memory and exploration of different levels of knowledge. [Fig.4]

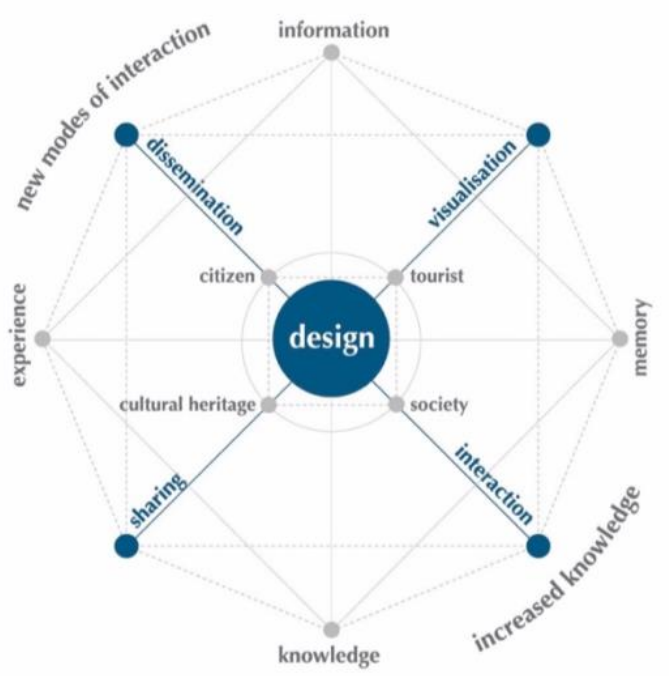

Fig. 4: Design for advanced connection. (Author, 2019)

The configuration of the city as an «advanced» digital place, therefore, no longer presents itself as a utopian or futuristic image. The skilful use of technologies integrated in the design of devices and services aimed at social welfare and the conscientious use of innovations, 
can help to shape a society that draws benefits for humanity from the relationship and collaboration between human and machine.

Through the reinterpretation of interaction technologies, the designer reorganizes the user's skills, increasing social knowledge and modifying the experiences and interpretation of urban contexts, to configure new forms of «humanization» of the interactive experience. [Fig.5]

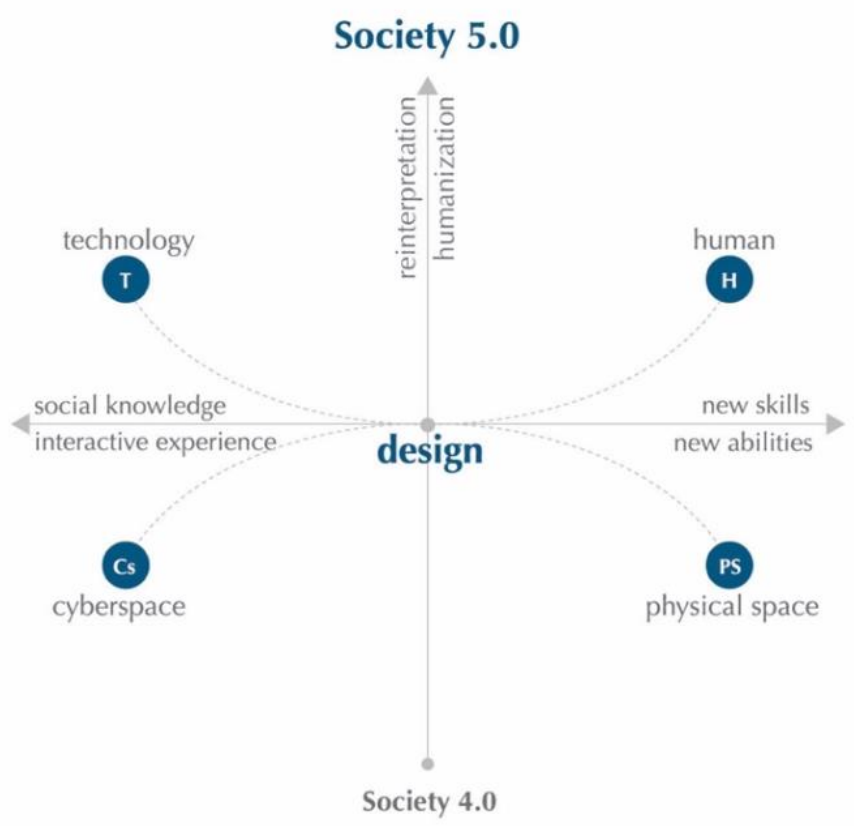

Fig. 5: Guidelines for designing new Connections and Interaction. (Author, 2019)

Design is needed that takes into account accessibility and digital usability for an «extended» user, through the use of new technologies and favours new forms of knowledge and cultural and social experience.

According to Khanna (2014) we are in the hybrid age, a new socio-technological era that emerges as technologies merge with each other and humans with them. The relationship with technology is moving beyond the purely instrumental level into the existential sphere. The influence of technologies follows a constantly accelerating centripetal trend. Technology no longer merely processes instructions in a one-way manner, instead it increasingly provides intelligent feedback.

These means transform the contemporary context into a smart one in which hybrid human-machine skills can lead to new forms of collaboration aimed at social welfare. 
To make society sustainable, intelligent and connected, and thus become a «Super Smart Society» (Matsushima, 2017), it will be necessary to find a new balance between human and technology and between physical space and cyberphysical space, aiming at a better quality of life. This is a new balance that requires us to be thinking humans.

\section{Conclusions}

The digitalization and virtualization of fruitive experiences determine new paradigms of interaction, reinterpreting and reconfiguring the classic channels of knowledge. The use of new technologies and tools in order to support the interconnection and dissemination of information configure new spaces for sharing reality and promoting knowledge that transcend physical boundaries. Therefore, it will be necessary to configure technological tools of communication and narration and models of cultural dissemination in order to enhance the user's fruitive experience and to promote the heritage, starting from new perceptivesensorial modes and new visions of heritage. (Giugliano \& Laudante, 2020) In this way it will be possible to guarantee a conscious and mature fruition of the Cultural Heritage by triggering actions of protection and safeguard as well as knowledge and enhancement. Planning in culture therefore implies the recognition of a context, of relationships, of dialogue, and therefore of the understanding of needs and expectations that require to be met in different ways at different levels of accessibility. (Zane, 2019) Design, seen as an experimental model for the human sciences, identifies new tools and methods for designing highly participatory experiences in a deeply cross-disciplinary dimension.

Designing relationships between technologies, society and users means experimenting new ways of transferring knowledge starting from dynamic and narrative structures configured according to contemporary techniques and tools. Through technological expedients, it will be possible to associate data to the people who generate them, to their behaviours and habits through investigative tools such as data visualisation data humanism (Lupi, 2017) to define a multidimensional scenario consisting of visual, spatial, acoustic and temporal information that characterise the user who lives the city. (Giugliano, Capece \& Buono, 2020)

The result of a needs-aware design is the construction of increasingly "performing» environments, suitable to be «experienced» by people with «different profiles», who move around interacting with each other and with the environment itself. (Garofolo \& Conti, 2012)

Project choices should therefore be focused on the growth of people and the 
development of new skills, to promote a society in which technology is an aid to humanity.

\section{Bibliography}

Capece, S., Giugliano, G. (2018). Communication and interaction models for the Cultural Heritage, in IX Conference of AIES "Diagnosis for the Conservation and Valorization of Cultural Heritage". Napoli: Cervino Edizioni

Endo, K., Kurihara, S., Kamihigashi, T., \& Toriumi, F. (Eds.). (2017). Reconstruction of the public sphere in the socially mediated age. Springer Singapore.

Flusser, Vilém (2003). Filosofia del design. Milano: Bruno Mondadori.

Garofolo, I., \& Conti, C. (Eds.). (2012). Accessibilità e valorizzazione dei beni culturali: temi per la progettazione di luoghi e spazi per tutti (Vol. 4). Milano: FrancoAngeli.

Granelli, A. (2016) Orizzonte 2030 - La Tecnologia. Retrieved October 15, 2020, from: http://www.agranelli.net/DIR_rassegna/ART_HBR_MacroTrends2016.pdf

Giugliano G., Capece S., Buono M. (2020). The Design for the connected and multisensory city, in Journal of Sustainable Mediterranean Construction. Land Culture, Research and Technology vol. 12 “2030 Sustainable Development Goals: city and land”, pp. 43-50. ISSN: $2420-8213$.

Giugliano G., Laudante E. (2020). Design as Collaborative Connection between User, Technology and Cultural Context in IOP Conference Series: Materials Science and Engineering, Volume 949, International Conference Florence Heri-tech: The Future of Heritage Science and Technologies, 14-16 oct 2020, Online Edition. ISSN.1757-899X

Keidanren (2016). Toward realization of the new economy and society. Retrieved July 03, 2019, from: https://www.keidanren.or.jp/en/policy/2016/029_outline.pdf.

Khanna, A., \& Khanna, P. (2014). L'età ibrida: il potere della tecnologia nella competizione globale. Codice.

Lupi, G. (2017). Data Humanism, the volution will be visualized. Retrieved February 22, 2020, from: https://medium.com/@ giorgialupi/datahumanism-the-revolution-will- bevisualized-31486a30dbfb\#. bh07dh315.

Maldonado, Tomás (1994). Reale e virtuale. Milano: Feltrinelli Editore.

Matsushima, K. (2017). La sfida della società 5.0. Retrieved May 05, 2019, from: https://www.considi.it/19345/. 
Morganti, Francesca \& Riva, Giuseppe (2006). Conoscenza, comunicazione e tecnologia. Aspetti cognitivi della realtà virtuale. Milano: Edizioni Universitarie di Lettere Economia Diritto.

Ratti, Carlo (2013) Smart city, smart citizen (Italian Edition). Egea.

Ratti, Carlo, \& Claudel, Matthew (2017). La città di domani: come le reti stanno cambiando il futuro urbano. Einaudi.

Salgues, Bruno (2018). Society 5.0: Industry of the Future, Technologies, Methods and Tools.

London: John Wiley \& Sons.

Zane, M. (2019) Tecnologie 4.0 per il "Sistema Cultura", Polo Tecnologico Lucchese, Gennaio 2019. 